\title{
BIOSSENSORES BASEADOS NO PROCESSO DE INIBIÇÃO ENZIMÁTICA
}

\section{Paulo Roberto Brasil de Oliveira Marques* e Hideko Yamanaka}

Departamento de Química Analítica, Universidade Estadual Paulista "Júlio de Mesquita Filho", Rua Francisco Degni, s/n, 14800-900 Araraquara - SP, Brasil

Recebido em 3/5/07; aceito em 30/11/07; publicado na web em 4/9/08

\begin{abstract}
BIOSENSORS BASED ON THE ENZYMATIC INHIBITION PROCESS. Fast, selective, reproducible and reliable detections have been carried out by using enzymatic biosensors in several areas. The enzymatic biosensors based on the inhibition represent an important role in analytical chemistry. Enzymes like cholinesterases, peroxidases, tyrosinases, etc. have been immobilized on electrochemical and optical transducers and the enzymatic activity decreasing in the presence of the inhibitor is related with its concentrations. This article presents a review on the enzymes used on the construction of these sensors, emphasizing the respective applications.
\end{abstract}

Keywords: enzymatic biosensor; enzymatic inhibition; bio-electrochemistry.

\section{INTRODUÇÃOO}

Os biossensores são sensores modificados com material biológico intimamente ligado à superfície de um transdutor. ${ }^{1,2}$ Quando este material é uma enzima, estes sensores são denominados biossensores enzimáticos, que, entre outros, podem fazer uso da atividade enzimática como sinal analítico a ser monitorado. ${ }^{3,4}$ Dentre os variados tipos, merecem destaque aqueles em que o monitoramento do analito é baseado no princípio de inibição da enzima, na qual a atividade é medida antes e após a inibição. Este processo é efetuado pela exposição da enzima a um inibidor específico, por um determinado tempo, sendo que a porcentagem de inibição sofrida pela enzima está quantitativamente relacionada com a concentração deste agente inibidor. ${ }^{5}$ Estes biossensores têm sido empregados em diversas áreas do conhecimento, como medicina, biologia, química, física e farmácia, bem como em distintos setores de aplicação, tais como monitoramento ambiental, medicina, setor militar, industrial e de saúde. ${ }^{6-9} \mathrm{~A}$ grande aplicabilidade está relacionada às vantagens referentes aos biossensores, podendo-se destacar: sensibilidade, respostas rápidas e baixo custo, alta especificidade, detecção de baixas concentrações do analito, número variável de enzimas disponíveis comercialmente, além de uma variedade de metodologias empregadas na construção destes sensores biológicos. A tecnologia atualmente empregada na construção de transdutores eletroquímicos, aliada aos diversos métodos analíticos descritos na literatura, vem colaborando sobre-maneira com o fortalecimento desta área específica de biossensores. ${ }^{10-14}$

Várias enzimas vêm sendo empregadas na construção destes sensores, podendo ser citadas colinesterases, ureases e tirosinases, dentre outras, em arranjos simples ou multi-enzimáticos, fazendo uso de distintos transdutores, como os amperométricos, conductimétricos e ópticos. ${ }^{15-20}$ Como analitos, têm sido investigadas distintas classes de inibidores enzimáticos potenciais como, por exemplo, metais pesados, pesticidas organofosforados e carbamatos, além de sulfitos, peróxidos, tiuréias, e outros. ${ }^{21-24}$

O presente artigo visa uma abordagem no que diz respeito aos processos de inibição, os tipos de biossensores, os procedimentos de confecção mais utilizados (transdutores, mediadores, processos de imobilização), as enzimas mais empregadas e os analitos estudados. Será dada ênfase aos biossensores enzimáticos com transdução eletroquímica, visto que são os mais empregados na literatura.

*e-mail: paulobrasil@iq.unesp.br

\section{O PROCESSO DE INIBIÇÃO ENZIMÁTICA}

O conceito biológico de inibidor enzimático diz respeito à substância que é capaz de interferir, de maneira específica, na taxa de uma reação de catálise enzimática, retardando ou reduzindo o processo ou a especificidade biológica da reação. Os processos de inibição de enzimas estão divididos em dois tipos, inibição reversível e inibição irreversível. A diferença básica está na formação do complexo enzima-inibidor, que pode ou não ser desfeito por etapas de diluição ou diálise, dependo do processo. ${ }^{25-28}$

\section{Inibição reversível}

Os inibidores reversíveis levam à formação de um complexo em um sistema em equilíbrio, no qual a enzima apresenta um grau definido de inibição, que é dependente das concentrações dos reagentes no meio (enzima, inibidor e substrato), permanecendo constante a partir de um tempo determinado. O processo de inibição reversível pode ser dividido em três tipos básicos, competitivo, não competitivo e incompetitivo.

\section{Competitivo}

Neste processo, o inibidor (I) geralmente apresenta características estruturais e afinidades semelhantes às do substrato $(S)$ ao qual ele está interferindo, competindo com este pelo mesmo sítio de ligação da enzima (E). Uma vez que este inibidor consegue se ligar à enzima, esta não o converte em produto $(\mathrm{P})$, levando à formação de um complexo inativo (EI), o que impede a enzima de efetuar nova catálise. Como o processo é reversível, a simples adição de uma maior quantidade de substrato pode deslocar o equilíbrio de modo a favorecer a formação do complexo enzima-substrato (ES), minimizando a probabilidade de uma molécula de inibidor se ligar à enzima. O processo de inibição reversível competitiva é descrito pela reação 1

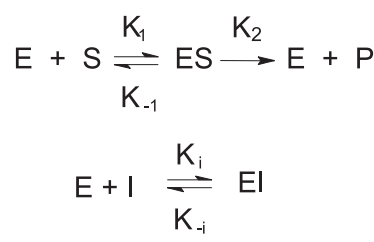

(reação 1)

onde a constante para a formação do complexo-inibidor também 
é conhecida como constante de inibição $\left(\mathrm{K}_{\mathrm{i}}\right)$, podendo expressar o grau de interação entre um respectivo inibidor enzimático e a enzima inibida. ${ }^{25}$

\section{Não competitivo}

Neste processo, o inibidor liga-se a um sítio diferente do sítio de ligação do substrato, o que indica que a inibição não pode ser revertida pela adição de quantidades de substrato. Ocorre a formação de complexos, tanto entre a enzima e o inibidor (EI), quanto entre este e o substrato (EIS). Um inibidor não competitivo apresenta um comportamento de remoção da enzima ativa da solução, o que resulta na diminuição da velocidade da reação, devido à quantidade de enzima livre. ${ }^{25} \mathrm{~A}$ reação 2 demonstra o processo de inibição não competitivo.

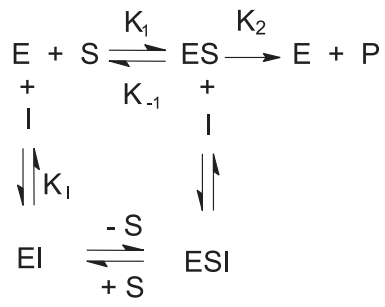

(reação 2)

\section{Incompetitivo}

Um inibidor incompetitivo é aquele que se liga somente ao complexo enzima-substrato formado. A ligação entre o inibidor e o complexo é efetuada por um sítio de ligação diferente do sítio em que o substrato se encontra ligado à enzima, como no caso do inibidor não competitivo, porém, no processo de não competitivo, como dito anteriormente, o inibidor se liga tanto à enzima livre, quanto ao complexo, o que não ocorre com o processo de inibição incompetitiva, em que o inibidor tem afinidade apenas pelo complexo formado. ${ }^{25} \mathrm{~A}$ reação 3 descreve o processo:

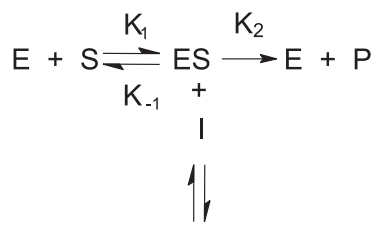

(reação 3)

ESI

\section{Inibição irreversível}

Neste processo, o inibidor liga-se ao sítio ativo da enzima de maneira irreversível, geralmente por formação de ligações covalentes, podendo até promover a destruição de grupos funcionais essenciais para a enzima. A inibição irreversível é progressiva, aumentando com o tempo, até atingir máxima inibição. Os inibidores irreversíveis são muito úteis em estudos de mecanismo de reação. ${ }^{25}$ A reação 4 representa o processo de modo geral:

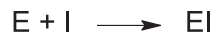

(reação 4)

\section{MATERIAIS EMPREGADOS}

A praticidade na construção de biossensores pode ser justificada pela gama de materiais que estão disponíveis. Para os biossensores eletroquímicos, a literatura relata variados tipos de eletrodos que vêm sendo empregados na confecção destes sistemas de biodetecção. ${ }^{2,3}$ No geral, a enzima é imobilizada na superfície do eletrodo de trabalho, sendo a atividade da enzima medida contra a adição de seu substrato na solução. As primeiras imobilizações constavam de membranas semipermeáveis, acopladas a eletrodos clássicos, como o de pH e o de Clark. ${ }^{1,4,29}$ Seguidamente, os eletrodos sólidos e metálicos foram então utilizados, como os de pastas de carbono, carbono vítreo, ouro e platina. ${ }^{2,3}$ Para os arranjos ópticos, diversos tipos de fibras têm sido empregados, com distintos formatos, fazendo uso das mesmas técnicas de imobilização empregadas nos sensores eletroquímicos, com poucas modificações. ${ }^{3}$

Apesar das vantagens, quando se trabalha com biossensores baseados em inibição, necessita-se de processos que possam regenerar a carga enzimática, do contrário, este sensor fica praticamente inutilizado e o processo de limpeza da superfície eletródica, bem como de imobilização da enzima deve ser refeito, o que pode acrescentar etapas longas e duradouras de otimização, o que não é interessante em estudos de biossensores. Diante destas desvantagens, sensores do tipo descartáveis têm sido apresentados como alternativas viáveis na construção de sistemas de biodetecção que possam ser rápidos, reprodutivos, sensíveis, baratos e de construção em grande escala, com possibilidades de miniaturização. ${ }^{30}$ Arranjos de eletrodos construídos empregando a técnica de screen printing ganharam lugar de destaque na literatura, nas últimas décadas. São sensores do tipo impressos ou serigrafados, onde as camadas sub-sequienciais eletródicas são depositadas sobre suportes finos, como cerâmica e plásticos, sendo que a enzima pode ser imobilizada sobre o eletrodo, em pequenas quantidades, por variadas metodologias, possibilitando tanto análises rápidas e baratas, quanto a aplicação in situ. .1-36 $^{31}$

\section{PROCESSO DE IMOBILIZAÇÃO}

Os primeiros estudos empregando enzimas como catalisadores em eletroanalítica avaliavam o seu comportamento em solução e vieram auxiliar no melhor entendimento de suas cinéticas de reações eletródicas. Contudo, o fato de que uma quantidade de enzima deveria ser novamente adicionada à solução, a cada nova medida, tornava os estudos muito dispendiosos financeiramente. ${ }^{32}$ Neste sentido, a imobilização da enzima ao transdutor veio eliminar esta desvantagem no estudo enzimático. A imobilização consiste em uma etapa crítica na construção de qualquer biossensor. Diversos procedimentos têm sido empregados na construção de biossensores enzimáticos, sendo que todos podem ser encaixados na classificação geral dos procedimentos de imobilização de material biológico (Figura 1), sendo: (a) adsorção; (b) encapsulação; (c) ligação covalente, e (d) ligação covalente cruzada (crosslinking).

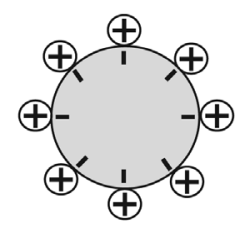

(A)

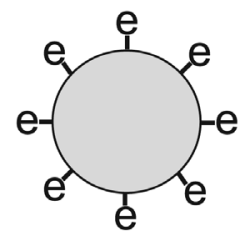

( C )

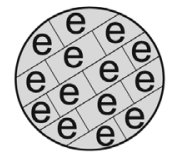

( B )

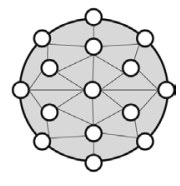

( D )
Figura 1. Esquema ilustrativo dos quatro tipos básicos de métodos de imobilização enzimáticos: a) adsorção; (b) encapsulação; (c) ligação covalente, e (d) ligação covalente cruzada 
Adsorção física da enzima é o modo mais simples e rápido de imobilização. Baseia-se em interações físicas entre a enzima e a superfície da matriz. Uma atividade muito próxima da natural é observada, sendo que as principais vantagens da adsorção são o baixo custo e a facilidade de imobilização. Devido às forças de ligação envolvidas resultantes da variação de temperatura, $\mathrm{pH}$ e força iônica, o baixo controle destes parâmetros é o principal problema, visto que as atrações podem ser facilmente desfeitas. ${ }^{2,3,31}$ Os métodos que empregam encapsulação são baseados no confinamento da enzima em uma membrana localizada na superfície do eletrodo. Esta membrana retém a enzima, apresentando porosidade controlada, de maneira a permitir a livre difusão do substrato e dos produtos da reação através da mesma. Numerosas membranas têm sido utilizadas: náilon, nitrato de celulose, acetato de celulose, resinas, colágeno e policarbonatos. As principais desvantagens estão associadas aos fenômenos de transferência de massa do substrato, aos produtos da reação e ao crescimento de microorganismos na superfície da membrana. Os métodos de oclusão são baseados no confinamento da enzima dentro dos espaços intersticiais de um gel, permitindo a livre difusão de substratos de baixo peso molecular e dos produtos da reação. ${ }^{2}$ Vários materiais têm sido utilizados para oclusão da enzima, tais como gel de poliacrilamida, álcoois polivinílicos, grupos catiônicos e aniônicos, entre outros. A principal desvantagem está associada às perdas na atividade enzimática por desnaturação, devido à presença de radicais livres. ${ }^{37}$

A técnica de imobilização mais utilizada tem sido a de formação de ligação covalente. A retenção da enzima na superfície do suporte é efetuada por ligações entre os grupos funcionais da enzima e a superfície do suporte. A desvantagem está na perda de parte da atividade enzimática, por conta das alterações nas conformações dos sítios ativos da enzima. ${ }^{38-41}$ A ligação covalente cruzada (crosslinking) é baseada na formação de um sistema reticulado das moléculas da enzima, formando uma rede rígida. Este processo oferece a vantagem de uma ligação enzima-enzima mais sólida, porém, pode induzir a formação de barreiras de difusão, resultando no aumento do tempo de resposta do biossensor. O glutaraldeído e o álcool polivinílico com grupos estirilpiridínicos (PVA-SbQ) ligados são exemplos de agentes de ligação cruzada utilizados na construção de biossensores. ${ }^{31,32}$

Nunes et al. ${ }^{32}$ compararam distintas metodologias de imobilização de enzimas acetilcolinesteases (AChE) em eletrodos impressos de grafite, empregando a ligação cruzada, com glutaraldeído em presença de soro albumina bovina e com álcool polivinílico modificado (PVA-SbQ). Foram utilizadas as técnicas de cronoamperometria e coulometria, para avaliação do processo e detecção de pesticidas n-metil carbamatos. A imobilização de AChE com glutaraldeído apresentou maior robustez e reprodutibilidade, mas, necessitando de maior carga enzimática imobilizada ( $80 \mathrm{mU} /$ eletrodo) que o sensor estudado com PVA-SbQ (0,7 mU/eletrodo). Li et al..$^{42}$ empregaram vapores de glutaraldeído como método de imobilização de enzimas acetilcolinesterases em eletrodos impressos. O coeficiente de variação (CV) para oito medidas de solução de substrato acetiltiocolina, na concentração de $7,5 \mathrm{mmol} \mathrm{L}^{-1}$, foi de $3,8 \%$, indicando boa reprodutibilidade do biossensor, que foi empregado para detecção de paraoxon, apresentando faixa de trabalho linear de $1,8 \times 10^{-7}$ a $5,4 \times 10^{-5} \mathrm{~mol}$ L"1. com $85 \%$ de inibição enzimática.

Reybier et al. ${ }^{43}$ construíram um biossensor potenciométrico para detecção de pesticidas organofosforados em água, imobilizando a enzima BuChE por reticulação com glutaraldeído, em filmes de polietilenamina eletropolimerizados na superfície de eletrodos de ouro e carbono vítreo. O limite de detecção alcançado pelo sistema foi abaixo de $1 \times 10^{-7} \mathrm{~mol} \mathrm{~L}^{-1}$, em tempos de equilíbrio dez vezes menores que outros biossensores potenciométricos apresentados na literatura. Díaz e Peinado ${ }^{39}$ construíram um biossensor para detecção óptica de pesticidas organofosforados, baseado em enzima AChE imobilizada pelo método de sol-gel. A enzima foi micro-encapsulada em géis de tetrametilortossilicato (TMOS), do qual foram formados finos que então foram imobilizados na superfície de fibras ópticas. A enzima catalisou a hidrólise do substrato indoxil-acetato, formando acetato e indoxil, sendo este último um produto fluorescente, o que permitiu o estudo de inibição enzimática através do monitoramento da atividade fluorescente no meio. A metodologia empregada foi satisfatória para o objetivo proposto, podendo ser efetuada a análise após $30 \mathrm{~min}$ de preparo do biossensor, que apresentou tempo de reposta de $5 \mathrm{~min}$.

O processo de imobilização de uma enzima sobre um suporte pode influenciar ou até modificar as respostas do biossensor. Cada metodologia pode apresentar vantagens, tanto quanto desvantagens, sendo que o melhor arranjo deve ser estudado e otimizado buscando resultar em um sensor que possa apresentar um sinal expressivo do processo analítico, com reprodutibilidade e repetibilidade adequadas.

\section{MONITORAMENTO DO PROCESSO DE INIBIÇÃO}

Os processos cinéticos de inibição de enzimas já vêm sendo estudados há várias décadas, objetivando compreender os seus mecanismos de ação, o que tem auxiliado na construção de sistemas analíticos. ${ }^{25-28} \mathrm{O}$ monitoramento efetuado para estes biossensores aqui descritos, como dito anteriormente, é baseado na capacidade que certos compostos têm de inibirem a reação natural de catálise realizada pela enzima. No geral, um sinal de base $\left(\mathrm{S}_{1}\right)$ é inicialmente medido com relação a uma solução contendo substrato, em concentração fixa definida e em ausência de inibidor. Posteriormente, o biossensor é mergulhado em uma segunda solução trabalho, por um tempo pré-determinado, na qual uma quantidade específica de inibidor se encontra presente. A etapa de inibição é então efetuada, sendo que a enzima imobilizada sofre um decréscimo em sua atividade. Em seguida, o sistema é colocado novamente em solução contendo o substrato enzimático (mesma concentração da solução 1) e o sinal de base $\left(\mathrm{S}_{2}\right)$ é novamente medido. Como este sinal é proporcional à concentração do substrato, este decréscimo na atividade enzimática leva a uma variação no sinal de base, que está relacionado com a quantidade de agente inibidor presente na solução na qual o biossensor foi mergulhado (segunda solução de trabalho). Desta forma, a quantidade de inibidor, que é variável durante uma análise, pode ser relacionada com a porcentagem de inibição (\%IR) obtida, visto que o aumento da quantidade de inibidor no meio reacional acarreta em um aumento na taxa de decréscimo da atividade enzimática. ${ }^{44,45}$ Esta porcentagem pode ser calculada pela relação matemática (Equação 1)

$\% \mathrm{IR}=\left[\mathrm{S}_{1}-\left(\mathrm{S}_{2} / \mathrm{S}_{1}\right)\right] \times 100$

Este processo pode ser monitorado por vários tipos de transdutores, dependo do sinal de grandeza a ser medido e amplificado. Para alguns arranjos de biossensores enzimáticos de inibição, a relação entre o substrato e o inibidor pode ser medida indiretamente. Podem ser utilizados no meio reacional, ou ainda imobilizados juntamente com a enzima, compostos susceptíveis de sofrerem algum tipo de variação em propriedades específicas, quando o sistema sofre interferência de um inibidor específico. Deste modo, esta variação pode ser relacionada com a quantidade de inibidor no meio, como no caso dos biossensores ópticos baseados em enzimas, que avaliam a variação de fluorescência.

Zhang, Zao e John ${ }^{46}$ estudaram as relações entre a porcentagem de inibição e o tempo de incubação e entre a porcentagem de inibição e a concentração do inibidor, efetuando considerações teóricas e práticas acerca do estudo. Os autores indicaram que uma relação linear entre a taxa de inibição e a concentração do inibidor foi obtida somente quando os sensores ofereceram reações sob condições de 
controle difusional, já a relação entre as medidas de sinal e a porcentagem de inibição foi somente alcançada sob condições cinéticas controladas.

Dependendo do tipo de inibidor estudado, bem como do processo de inibição a ser monitorado, o biossensor pode ser empregado para diversas determinações. Se o agente de inibição efetuar um processo reversível para com a enzima, o sensor pode ser reutilizado, após tratamento específico da camada biológica imobilizada, regenerando a capacidade catalítica do biossensor. Caso o inibidor exerça uma inibição irreversível, o sistema apresenta a limitação do uso de apenas uma carga enzimática específica a ser trabalhada por sensor, visto que, com a total inativação desta carga, o biossensor não mais apresenta o processo analítico a ser monitorado.

\section{TIPOS DE BIOSSENSORES BASEADOS EM INIBIÇÃO}

A literatura não relata uma classificação específica para estes tipos de biossensores, então, foram aqui classificados de acordo com a enzima imobilizada. Neste aspecto, algumas enzimas têm sido utilizadas para a construção destes sensores, podendo destacar as colinesterases (AChE e BuChE) e a tirosinase (Tyr), dentre outras, que têm sido apresentadas como ferramentas promissoras para investigação de analitos pelo monitoramento do processo de inibição.

\section{Biossensores baseados em enzimas colinesterases}

Os biossensores baseados nos mecanismos de inibição de enzimas colinesterases (ChE) estão entre os biossensores de inibição mais empregados na literatura e vêm, nas últimas décadas, merecendo atenção por parte da comunidade científica. São sistemas rápidos, seletivos, sensíveis, de fácil uso, com tempo de resposta bastante curto e necessitando de mínimo tratamento da amostra, além das possibilidades de efetuar análises quantitativas e qualitativas em tempo real. ${ }^{47-49} \mathrm{~A}$ facilidade de obtenção das enzimas colinesterases na forma comercial torna-se um grande atrativo para a construção destes arranjos de sensores. As colinesterases são importantes enzimas presentes nos invertebrados e nos insetos, atuando no sistema nervoso central, controlando impulsos e transmissões dos estímulos nervosos. Estão divididas em duas classes, sendo: acetilcolinesterase (EC 3.1.1.7)(AChE) e butirilcolinesterases (EC 3.1.1.8)(BuChE), estas últimas também conhecidas como pseudocolinesterases, pois possuem estrutura similar à acetil-colinesterase, porém, com especificidade diferente de substrato. As AChE são enzimas da classe das hidrolases, sendo que a hidrólise do seu substrato natural, o neurotransmissor acetilcolina (AX), se processa formando o complexo enzima substrato $(\mathrm{EH}-\mathrm{AX})$, produzindo posteriormente a molécula de colina (HX) e a enzima acetilada (EA), hidrolisando rapidamente a ácido acético $(\mathrm{AOH})$, liberando então a enzima livre (EH), de acordo com a reação 5 :

$$
\begin{gathered}
\mathrm{EH}+\mathrm{AX} \rightleftharpoons \mathrm{EH} \cdot \mathrm{AX} \longrightarrow \mathrm{HX}+\mathrm{EA} \\
\mathrm{EA}+\mathrm{H}_{2} \mathrm{O} \longrightarrow \mathrm{EH}+\mathrm{AOH}
\end{gathered}
$$

As colinesterases também hidrolisam ésteres de tiocolina, tais como acetiltiocolina, butiriltiocolina, propioniltiocolina, acetil$\beta$-metiltiocolina, bem como $o$-nitrofenilacetato, indofenilacetato e $\alpha$-naftilacetato. As BuChE possuem preferência por butiril ésteres, como a butirilcolina. ${ }^{50}$ Os mecanismos de inibição destas enzimas já se encontram bem difundidos na literatura e têm sido utilizados como ferramentas para a construção de biossensores para monitoramento de compostos tóxicos, como os pesticidas organosfosforados e carbamatos, a nicotina e os metais pesados, constituindo uma alternativa aos métodos comumente utilizados em química analítica, como os métodos cromatográficos e os espectrofotométricos. Os pesticidas organofosforados e os carbamatos estão entre os compostos potencialmente tóxicos mais estudados por estes sistemas de biodetecção. A reação das enzimas colinesterases com estes inibidores é similar àquela que ocorre com o seu substrato natural (AX), porém, o complexo enzima-inibidor formado não permite o retorno da enzima livre para o meio reacional. ${ }^{45}$ Para a inibição com os organofosforados (PX), a enzima fosforilada formada é estável, o que resulta em um processo de inibição irreversível, segundo a reação 6:

$$
\mathrm{EH}+\mathrm{PX} \rightleftharpoons \mathrm{EH} \cdot \mathrm{PX} \longrightarrow \mathrm{EP}+\mathrm{HX}
$$

Para os pesticidas carbamatos, este processo de inibição é considerado reversível, visto que o complexo enzima-inibidor formado pode ser desfeito, sob condições especificas de equilíbrio entre as concentrações da enzima e do inibidor. Espontaneamente, a colinesterase carbamilada é fracamente hidrolisada, de tal modo que a inibição pode ser revertida. Os biossensores baseados em enzimas colinesterases mais estudados são os amperométricos, visto que a metodologia possui possibilidades reais de automação e miniaturização. Como suportes, estes arranjos de sensores têm utilizado grafite, carbono, carbono vítreo, pasta de carbono, nanotubos de carbono, além de metais nobres, como o ouro, sendo tanto na forma de eletrodos convencionais, como de sistemas alternativos, como os do tipo impressos..$^{50}$

A primeira geração de biossensores de colinesterases empregava sensores amperométricos bi-enzimáticos baseados em colinesterase e colina oxidase $(\mathrm{ChO})$. Inicialmente, a enzima $\mathrm{ChE}$ hidrolisa o substrato natural a colina e acetato, então a segunda enzima, colina oxidase, era usada para produzir peróxido de hidrogênio, que é facilmente detectado por amperometria $(+650 \mathrm{mV}$ versus $\mathrm{Ag} / \mathrm{AgCl})$. A problemática envolvida no processo é que os potenciais de estudo aplicados são muito elevados, o que torna este tipo de biossensor muito sujeito à interferência de outras espécies eletroativas indesejadas, que possam estar presentes no meio. ${ }^{51,52} \mathrm{O}$ segundo processo envolvia o uso do eletrodo e Clark para medir o consumo de oxigênio na reação catalisada pela $\mathrm{ChO}$ (reação 7).

$$
\begin{aligned}
& \text { acetilcolina ou butirilcolina } \stackrel{\mathrm{ChE}}{\mathrm{H}_{2} \mathrm{O}} \text { colina }+ \text { acetato } \\
& \qquad \begin{aligned}
\text { colina }+\mathrm{H}_{2} \mathrm{O}+1 / \mathrm{O}_{2} \stackrel{\mathrm{ChO}}{\longrightarrow} \text { colina oxidada }+\mathrm{H}_{2} \mathrm{O}_{2} \quad \text { (reação 7) } \\
\mathrm{H}_{2} \mathrm{O}_{2} \longrightarrow \mathrm{O}_{2}+2 \mathrm{H}^{+}+2 \mathrm{e}^{-}
\end{aligned}
\end{aligned}
$$

Para estes biossensores, geralmente a ChO é usada em excesso e a quantidade de AChE é otimizada em condições cinéticas controladas, podendo as duas enzimas serem co-imobilizadas na mesma matriz ou em matrizes diferentes, ou ainda fazer uso de imobilização de apenas uma das enzimas, disponibilizando a outra em solução, porém, limites de detecção mais baixos podem ser alcançados com o sistema de coimobilização das duas enzimas. Os potenciais de trabalho aplicados nestes sistemas têm variado de 500 a 700 mV, vs Ag/AgCl. Paration, paraoxon, carbofuran, aldicarb e malation são exemplos de pesticidas que têm sido detectados por este tipo de biossensor, em limites que alcançam $0,03 \mathrm{ppb}$

Kok e Hasirci ${ }^{51}$ co-imobilizaram AChE e ChO em membranas de poli(2-hidroxietil metacrilato)(pHEMA), em eletrodos de oxigênio, construindo um biossensor para detecção de pesticidas carbamatos, avaliando o comportamento destes isoladamente em solução e em soluções binárias dos pesticidas, objetivando avaliar as diferenças entre estes dois sistemas, visto que estas enzimas não são seletivas 
aos pesticidas, porém, à classe a que eles pertencem. Eles demonstraram que a atividade anticolinesterase apresentada pelo biossensor foi menor para o sistema binário, que para o somatório das atividades anticolinesterases individuais, indicando que uma mesma gama de amostras reais pode fornecer respostas distintas quando contaminada por mais de um pesticida. Palchetti et al. ${ }^{36}$ estudaram a atividade anticolinesterase de pesticidas organofosforados e carbamatos em soluções padrões e em amostras reais, avaliando o efeito de solventes orgânicos no meio. As curvas de calibração apresentaram comportamentos diferentes, quando distintos solventes orgânicos estavam presentes no meio, sendo que o acetato de etila foi o que mais afetou a atividade enzimática, evidenciando efeitos de inibição deste solvente sobre o biossensor. Guerrieri e Palmisano ${ }^{52}$ utilizaram um biossensor bi-enzimático como detector de um sistema cromatográfico, imobilizando acetilcolinesterase e colina oxidase em eletrodos de platina, por crosslink com glutaraldeído, constituindo uma nova alternativa aos detectores cromatográficos e possível aplicação destes sensores em cromatografia.

A segunda geração de biossensores à base de colineterases empregava apenas uma enzima imobilizada e fazia uso de substratos não específicos, baseando-se na direta detecção da tiocolina produzida no meio reacional, pela técnica de amperometria (reação 8). ${ }^{50}$ Neste tipo de arranjo, o uso de apenas uma enzima facilita a construção e o desenho do biossensor, além de que o potencial de trabalho aplicado é mais baixo, em torno de $450 \mathrm{mV}$, comparado com aquele aplicado para o peróxido de hidrogênio, minimizando assim, efeitos de interferentes.

acetilcolina ou butirilcolina $\frac{\mathrm{ChE}}{\mathrm{H}_{2} \mathrm{O}}$ tiocolina + acetato
2(acetilcolina ou butirilcolina) $\underset{v s \mathrm{Ag} / \mathrm{AgCl}}{\stackrel{+400 \mathrm{mV}}{\mathrm{V}} \text { ditio-bis-colina }+2 \mathrm{H}^{+}+2 \mathrm{e}^{-} \text {(reação 8) }}$

A terceira geração faz uso de mediadores eletroquímicos levando a um melhoramento significante na versatilidade de construção destes sistemas, visto que o potencial de trabalho passou então a ser função deste mediador e não mais dos substratos empregados ou dos reagentes gerados no meio reacional, além do que os biossensores à base de mediadores são menos susceptíveis a interferentes, pois o potencial de oxidação aplicado é menor. Os mediadores são imobilizados na superfície do eletrodo, na mesma matriz que a enzima que será inibida, ou em matriz diferente, objetivando uma rápida transferência eletrônica (Figura 2).

Nunes et al. ${ }^{53}$ estudaram a determinação de carbamatos em água, frutas e vegetais, com um sensor do tipo impresso, o qual continha como eletrodo de trabalho, pasta de carbono modificada com ftalocianina de cobalto, ao qual a enzima AChE foi imobilizada via ligação cruzada com glutaraldeído. A reação foi amperometricamente monitorada em potencial de $350 \mathrm{mV}$ vs Ag/AgI. Os estudos foram comparados com ensaios cromatográficos. O sistema apresentou alta sensibilidade e boa seletividade em diferentes matrizes analisadas, com limites de detecção de 0,657 e $0,452 \mathrm{mmol} \mathrm{L}^{-1}$, para os analitos carbaril e carbofuram, respectivamente. Rippeth et al. ${ }^{54}$ efetuaram estudos com enzimas $\mathrm{AChE} \mathrm{e} \mathrm{BuChE,} \mathrm{também} \mathrm{em} \mathrm{eletrodos} \mathrm{impressos}$ modificados com ftalocianina de cobalto para detecção de pesticidas paroxon e diclorvos. Bucur et al..$^{55}$ construíram um biossensor de colinesterase de alta afinidade com o pesticida carbamato, onde o eletrodo de trabalho foi baseado em pasta de carbono modificada com o mediador 7',8,8'-tetraciano-quinodimetano (TCNQ). O potencial de trabalho aplicado foi de $100 \mathrm{mV} v s \mathrm{Ag} / \mathrm{AgCl}$. Os limites de detecção alcançados foram de $2 \times 10^{-8}$ e de $8 \times 10^{-10} \mathrm{~mol} \mathrm{~L}^{-1}$, para o pirimicarb e para o carbofuran, respectivamente.

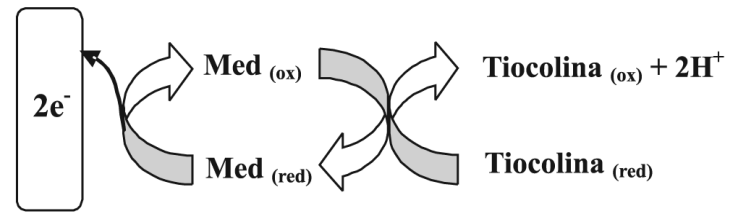

Figura 2. Detecção direta da tiocolina, utilizando mediador eletroquímico

Pode-se citar ainda, como mediadores utilizados na construção destes sistemas de detecção, o azul de metileno, o azul de meldola e o azul da Prússia. Ricci e Palleschi ${ }^{56}$ apresentaram uma revisão a cerca do preparo, otimização e aplicação de biossensores mediados com azul da Prússia, indicando duas aplicações nas áreas médicas, ambientais e de alimentos. Sistemas mais recentes fazem uso da transferência eletrônica direta do sítio catalítico da enzima para com o eletrodo, sendo este próprio eletrodo o mediador do processo eletroanalítico. ${ }^{57}$ Estas configurações de biossensores baseados no processo de inibição de enzimas colinesterases vêm sendo estudadas ao longo das duas últimas décadas, com variações nos mediadores utilizados, bem como nos substratos relativos a enzimas colinesterases. O tipo de transdutor, bem como a metodologia de detecção a ser empregada na construção destes sensores à base de colinesterases possuem dependência da escolha do substrato, do sistema enzimático e da aplicação final deste sistema, que está associada, na sua grande maioria, à detecção de pesticidas organofosforados e carbamatos e de metais pesados, tanto na área ambiental, quanto na de alimentos. ${ }^{9,15,21,58}$ Estes poluentes/contaminantes têm sido detectados em baixos limites, em distintas matrizes, tais como águas naturais (rio, mar, oceano, lagos), água de abastecimento, sedimentos, solos, além de diversos vegetais e alimentos. Áreas como a saúde e militar são potenciais de aplicação destes biossensores. . $^{36,41,59-61}$

Hart, Collier e Janssen, ${ }^{62}$ avaliando a resposta de biossensores baseados em colinesterases frente a formulações comerciais contendo organofosforados, indicaram que o sistema pode ser uma plataforma viável para aplicações em indústrias, nas áreas de controle de qualidade. Kumaran e Morita ${ }^{59}$ aplicaram um biossensor construído com enzima butirilcolinesterase imobilizada em membrana, acoplada a eletrodo de $\mathrm{pH}$, na detecção de organofosforados extraídos de amostras de solos, demonstrando a potencialidade deste sistema para aplicação em análise desta complexa matriz.

Além da variedade de construção, as aplicações podem, ainda, contar com o uso de técnicas acopladas, como no caso das análises em fluxo, que vêm somar significativamente com os sistemas de detecção. Nikolelis et al.$^{63}$ avaliaram a detecção do pesticida carbofuran em alimentos, por meio de análise por injeção de fluxo (FIA), onde a enzima colinesterase foi incorporada a filmes lipídicos. A detecção do pesticida foi efetuada entre $10^{-7}$ e $10^{-9} \mathrm{~mol} \mathrm{~L}^{-1}$. O efeito de interferente foi avaliado com relação a proteínas e lipídios usualmente encontrados nas matrizes estudadas (50 tipos diferentes de frutas e verduras) e os estudos de recuperação apresentaram índices de 96 a 106\%. Gunther et al. ${ }^{64}$ estudaram a detecção de carbofuran, paraoxon, malaoxon e metil paroxon, em eletrodos de platina, também por FIA, comparando com análise espectrofotométrica convencional, apresentando limite de detecção de $7 \mu \mathrm{g} \mathrm{L}^{-1}$ de pesticida. Ghous et al ${ }^{65}$ aplicaram o sistema FIA em biossensores de colinesterases inibidos com neostigmina e galantamina, encontrando limites de detecção de $0,5 \times 10^{-7}$ e $5,0 \times 10^{-7} \mathrm{~mol} \mathrm{~L}^{-1}$, respectivamente. Estudos de validação vêm sendo apresentados na literatura, buscando comparar os resultados apresentados pelos biossensores com os obtidos por técnicas comumente empregadas em química analítica, como a cromatografia e a espectrofotometria. Marty et al.$^{66}$ compararam estudos de detecção de fenitrotion, fenamifos, etil paration, carbaril pelas técnicas de 
amperometria com biossensores e cromatografia, em amostras de água. Evidenciou-se que os biossensores são técnicas potenciais de detecção destes pesticidas em baixos níveis de concentração, sendo uma metodologia de screening confiável, servindo de alarme para uma investigação posterior mais apurada por cromatografia.

Algumas contribuições em sistemas com transdutores ópticos também são apresentadas na literatura, sendo sensores bastante sensíveis e seletivos, com capacidade de monitoramento remoto, de fácil miniaturização e não sofrendo interferências de campos elétricos. ${ }^{67,68}$ Andreou e Clonis ${ }^{69}$ desenvolveram um biossensor de fibra óptica portátil para determinação de diclorvós e carbaril em amostras de água, a partir de enzimas colinesterases imobilizadas em membranas. O método apresentou reprodutibilidade da ordem de $5 \%$ (RSD), com limites de detecção de 108 e 5,2 $\mu \mathrm{g} \mathrm{L}^{-1}$, respectivo aos pesticidas citados. A precisão do método foi de $94,9 \%$, avaliada por estudos de recuperação. Choi et $a l .{ }^{70}$ efetuaram estudos em sensores de fibras ópticas com AChE imobilizadas em filmes finos, para a detecção de compostos organofosforados em água. O processo foi baseado no uso do substrato $O$-nitrofenil acetato, que na presença de AChE é convertido a um produto amarelo, $O$-nitrofenol. Na ausência de inibidor, o substrato é completamente hidrolisado, enquanto que na presença deste inibidor a intensidade de cor amarela diminui. Deste modo, trocas na absorbância do meio foram relacionadas com os teores dos compostos inibidores, não sendo afetados por variações de $\mathrm{pH}$. Os autores relataram a detecção de 2 ppm do pesticida paraoxon. Andres e Narayanaswamy ${ }^{71}$ avaliaram um biossensor óptico baseado em colinesterase imobilizada covalentemente em fibras óticas para a detecção de paraoxon e carbofuran. A resposta do sensor foi bastante reprodutível (CV 2\%). O limite de detecção foi de $1,5 \times 10^{-8}$ e 1,1 $1 \times 10^{-7}$ mol L ${ }^{-1}$, respectivamente.

Atualmente, enzimas colinesterases mutantes vêm sendo testadas, visando, a partir da modificação genética da enzima, melhorar a sensibilidade destes sensores, buscando construir biossensores cada vez mais seletivos a pesticidas específicos. ${ }^{50} \mathrm{~A}$ enzima acetilcolinesterase de Drosophila melanogaster (Dros) tem sido descrita na literatura para este fim. Nunes et al. ${ }^{72}$ avaliaram o comportamento de um biossensor construído com enzimas AChE (Dros) frente ao pesticida metamidofós. Diversas variantes das enzimas foram avaliadas cineticamente, via espectrofotometria, sendo selecionada a que apresentou uma maior inibição pelo pesticida testado, posteriormente, esta enzima foi imobilizada via ligação cruzada com álcool polivinílico modificado (PVA-SbQ), em eletrodos de carbono, modificado com sais de TCNQ. O sistema apresentou boa reprodutibilidade, com coeficientes de variação abaixo dos 5\%. A curva analítica construída forneceu limite de detecção de $9,93 \times 10^{-9} \mathrm{~mol} \mathrm{~L}^{-1}$. Marques et al. ${ }^{73}$, também trabalhando com o pesticida metamidofós, efetivaram uma investigação comparativa entre biossensores construídos a partir de enzimas comerciais e de enzimas geneticamente modificadas (Dros). Vinte e quatro variantes de Dros foram inicialmente avaliadas para a seleção das variantes mais sensíveis ao pesticida. Dezesseis apresentaram sensibilidade comparada às AChE disponíveis comercialmente, sendo que seis variantes foram insensíveis ao metamidofós e duas não apresentaram atividade. A variante mais sensível ao pesticida foi imobilizada em eletrodos de carbono de sensores impressos. O sensor construído com esta enzima geneticamente modificada mostrou-se melhor que os construídos com enzimas comerciais, com limite de detecção menor de $1 \mathrm{ppb}$, comparado com o de $90 \mathrm{ppb}$ apresentado para o sistema comercial.

Uma aplicação promissora para os biossensores de colinesteases está na detecção de toxinas, como as anatoxinas, que são organofosfatos naturais, que inibem as colinesterases, de maneira similar aos pesticidas organofosforados sintéticos. Estudos com enzimas AChE obtidas a partir da técnica de DNA recombinante e estudos baseados na não reativação do processo de inibição vêm sendo avaliados, com resultados promissores. Outra proposta é a detecção de compostos extremamente tóxicos, como o gás sarin, que age de mesmo modo que os pesticidas no organismo. Estes estudos estão sendo desenvolvidos por laboratórios militares e suas divulgações ainda não estão disponíveis. ${ }^{50}$

\section{Biossensores baseados em enzimas tirosinases}

Os biossensores baseados em enzimas tirosinases (fenol oxidase) têm sido bastante empregados na detecção de poluentes, sendo considerados os mais utilizados depois dos sensores modificados com colineterases. A tirosinase (EC 1.14.18.1) (Tyr) é uma metaloproteína binuclear, que possui cobre como grupo prostético e que catalisa a hidroxilação de monofenóis a $O$-diidróxi fenóis, com posterior oxidação a O-quinonas, necessitando de oxigênio como receptor de elétrons (reação 9). ${ }^{74}$

$$
\begin{aligned}
& \text { monofenol }+1 / 2 \mathrm{O}_{2} \underset{-\mathrm{H}_{2} \mathrm{O}}{\stackrel{\text { tirosinase }}{\longrightarrow}} \text { O-benzenodiol } \\
& \text { O-benzenodiol }+\mathrm{O}_{2} \underset{\text { tirosinase }}{\stackrel{-\mathrm{H}_{2} \mathrm{O}}{\longrightarrow}} \text { O-quinona }
\end{aligned}
$$

Neste aspecto, o monitoramento de oxigênio ou da redução da quinona gerada (Figura 3) podem ser empregados como processos de reconhecimento do sensor à base de tirosinase. Este procedimento apresenta mais vantagens, perante o monitoramento do oxigênio do meio, visto que o potencial aplicado é bem mais baixo. ${ }^{74} \mathrm{~A}$ dopamina também pode ser utilizada como substrato para a tirosinase, como demonstrado nos sensores construídos para detecção de atrazina. ${ }^{75}$

A tirosinase pode ser inibida por uma gama de poluentes, tais como carbamatos, organofosforados, ditiocarbamatos, atrazinas, tiuréas, ácidos carboxílicos aromáticos, triazinas, herbicidas, clorofenóis e agentes quelantes de cobre. ${ }^{75-86}$ Desta forma, biossensores baseados em enzimas tirosinases podem ser empregados com biossensores baseados em inibição enzimática, detectando tanto o decrescimento da quantidade de oxigênio no meio reacional, quanto a formação da quinona, em presença do agente inibidor. Eletrodos de carbono, ouro, ouro modificado e eletrodos de Clark têm sido empregados na construção destes sensores. Everret e Rechnitz ${ }^{87}$ investigaram a determinação de pesticidas diazinon e diclorvos, por meio de tirosinase imobilizada em eletrodos de oxigênio. A transferência eletrônica foi mediada pelo composto 1,2-naftoquinona-4 sulfonato, sendo utilizadas as técnicas amperométricas e coulométricas para este estudo de inibição. Os limites de detecção foram de $5 \mu \mathrm{mol} \mathrm{L}{ }^{-1}$ para o diazinon e de $75 \mathrm{nmol} \mathrm{L}^{-1}$ para o diclorvos. Serra et al. ${ }^{88}$ comparam três diferentes matrizes rígidas para a construção de um biossensor baseado em tirosinase imobilizada, sendo estas matrizes compostas por grafite-teflon; carbono vítreo reticulado-resina epóxi e grafitepolímero etileno/propileno/dieno (EPD). A melhor reprodutibilidade do sensor foi obtida com grafite-EPD. O sensor foi aplicado para detecção de compostos fenólicos. Deng e Dong ${ }^{89}$ demonstraram a aplicação de um biossensor baseado em tirosinase, para a detecção de ácido benzóico, 2-mercaptoetanol e tiuréia, em meio de solvente orgânico (clorofórmio e clorobenzeno, com perclorato de tetrabutilamônio-TBAP como eletrólito). O fenol foi utilizado como substrato enzimático. O biossensor apresentou máxima eficiência em clorofórmio puro. Campanella et al..$^{90}$ determinaram triazina, também fazendo uso de biossensores em fase orgânica de clorofórmio. O limite de detecção encontrado para o sistema inibidor foi de $0,5 \times 10^{-6} \mathrm{~mol}$ $\mathrm{L}^{-1}$. Estudos de recuperação em amostras de vegetais apresentaram valores acima de $90 \%$. 


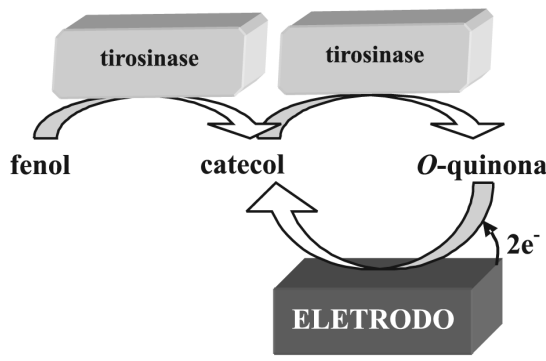

Figura 3. Princípio de amplificação do sinal bioeletrocatalítico para o sistema de biossensores baseados em enzimas tirosinase

Arranjos bi-enzimáticos, onde a enzima tirosinase é co-imobilizada com enzimas do tipo peroxidase (HRP) têm sido apresentados na literatura. Chang et al. construíram um sensor para detecção de compostos fenólicos, baseado em enzimas HRP imobilizadas em sensores do tipo impressos, com eletrodos de trabalho em carbono modificados com enzimas tirosinases. A composição do tampão, $\mathrm{pH}$, potencial operacional e estabilidade do sistema foram avaliados. Limites de detecção de compostos fenólicos foram encontrados em concentrações na faixa de $n m o l \mathrm{~L}^{-1}$.

\section{Peroxidase}

Enzimas peroxidases (HRP) (E.C. 1.11.1.7) também podem ser susceptíveis aos processos de inibição. O mecanismo catalítico da HRP pode ser descrito como demonstrado na reação 10 :

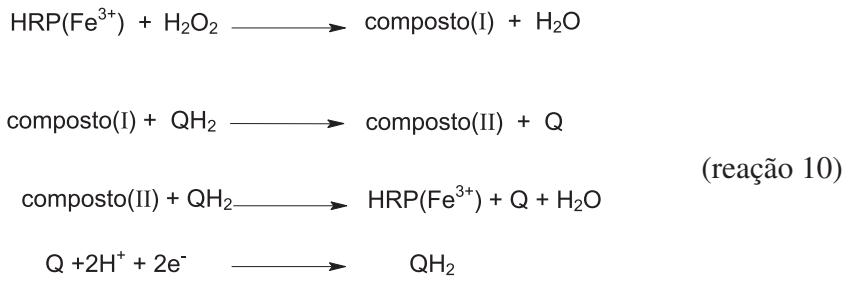

onde o $\mathrm{Fe}^{3+}$ é o cofator da HRP, os compostos I e II representam os intermediários da reação, sendo os estados enzimáticos de oxidação $+5 \mathrm{e}+4$, respectivamente, $\mathrm{QH}_{2}$ pode ser qualquer doador de elétrons, como a hidroquinona e $\mathrm{Q}$, a benzoquinona. O composto I é reduzido a composto II e o composto II a $\mathrm{HRP}\left(\mathrm{Fe}^{3+}\right)$, pelo mediador $\mathrm{QH}_{2}$. A benzoquinona é, então, rapidamente reduzida no eletrodo a hidroquinona. A corrente de redução é proporcional à concentração de $\mathrm{H}_{2} \mathrm{O}_{2}$ no meio (mantendo-se a concentração do doador de elétrons constante), sendo que esta corrente pode ser relatada em termos de atividade enzimática. ${ }^{92}$ Quando um inibidor é introduzido no meio reacional, como no caso dos sulfitos, ele pode se coordenar com o composto I intermediário, o que acarreta em decréscimo da atividade enzimática e conseqüente decréscimo no sinal de corrente. $\mathrm{O}$ procedimento pode ser descrito como uma inibição incompetitiva.

Adeyojo et al. ${ }^{93}$ avaliaram estudos de construção de biossensores baseados em enzimas peroxidases imobilizadas em polímeros do tipo Eastman AQ, com dimetilferroceno como mediador da reação catalítica do substrato peróxido de butanona (BTP). As medidas de inibição foram efetuadas com os inibidores tiuréia e etilinotiuréia. Os autores fizeram uso da técnica de voltametria cíclica, sendo que a eficiência catalítica do biossensor foi determinada pela razão da corrente de pico. O estudo também foi efetuado em meio de solventes orgânicos (acetonitrila, metanol e acetona). Um decréscimo na performance do biossensor foi observado com o aumento do caráter hidrofílico do solvente (metanol>acetonitrila>acetona), provavelmente devido à remoção da água de hidratação do sítio catalítico da enzima, o que pode causar desnaturação do mesmo, diminuindo a eficiência catalítica, acarretando em decréscimo no desempenho do biossensor. Han et al..$^{94}$ desenvolveram um biossensor baseado em HRP imobilizada em misturas de colóides, contendo polímero $\beta$-ciclodextrina ( $\beta$-CDP) e azul de metileno (mediador). O sistema foi utilizado para detecção de mercúrio. Neste caso específico, a inibição foi reversível e não competitiva em presença de cloreto de mercúrio (II), em menos de 8 s e irreversível, inativando a enzima, quando incubada em diferentes concentrações do mesmo reagente, em tempos acima de $1 \mathrm{~min}$. O limite de detecção foi de $0,1 \mathrm{nmol} \mathrm{L}{ }^{-1}$, de $\mathrm{Hg}$.

\section{Fosfatase}

Pesticidas organofosforados e carbamatos podem inibir a reação de hidrólise da glucose-6-fosfato catalisada pela enzima fosfatase ácida (AP) (E.C. 3.1.3.2), sendo este um processo reversível. A detecção amperométrica desta inibição requer um sistema bi-enzimático com glucose oxidase (GOD), de acordo com a reação 11:

$$
\begin{aligned}
& \text { glicose-6-fosfato }+\mathrm{H}_{2} \mathrm{O} \stackrel{\mathrm{AP}}{\longrightarrow} \text { glicose + fosfato inorgânico } \\
& \text { glicose }+\mathrm{O}_{2} \stackrel{\mathrm{GOD}}{\longrightarrow} \text { glicolactona }+\mathrm{H}_{2} \mathrm{O}_{2}
\end{aligned}
$$

sendo monitorado o peróxido de hidrogênio, em eletrodos de Clark, e a corrente medida proporcional à concentração de enzima.

Mazzei e Botrè ${ }^{95}$ estudaram estes arranjos de biossensores para determinar pesticidas organofosforados. A enzima AP foi imobilizada em membranas de diálise e a glucose oxidase em membranas de nylon. As medidas de inibição foram efetuadas com os inseticidas paraoxon, metil paration e malation, com limites de detecção de 1,5; 0,5 e 1,5 $\mu \mathrm{g} \mathrm{L}^{-1}$, respectivamente. A quantificação de microcistinas também tem sido avaliada por este sistema enzimático. ${ }^{96-98}$

\section{OUTRAS ENZIMAS}

A literatura apresenta alguns artigos a respeito da construção de biossensores baseados no processo de inibição enzimática, descrevendo outros tipos de arranjos enzimáticos. ${ }^{99-106} \mathrm{~A}$ Tabela 1 apresenta uma relação destas enzimas, de seus substratos, bem como as reações catalisadas e os possíveis inibidores a serem estudados.

\section{REGENERAÇÃO}

O entendimento do mecanismo de inibição enzimática é de grande importância para a construção de biossensores enzimáticos. A forma como enzimas peroxidase e tirosinase são inibidas está baseada no bloqueio dos sítios ativos destas enzimas, com a formação do complexo enzima-inibidor, o que bloqueia a transferência eletrônica entre a enzima imobilizada e o seu respectivo substrato. Pesticidas organofosforados bloqueiam a serina no sítio ativo das enzimas colinesterases, através de ataque nucleofílico. Estes procedimentos ainda constituem limitações na aplicação destes biossensores. Dentro deste contexto, estudos têm buscado a regeneração deste material biológico imobilizado na superfície do transdutor, visando uma maior versatilidade destes sistemas, efetivando a possibilidade de várias detecções em um único dispositivo. ${ }^{5}$

Para reativação da atividade catalítica da $\mathrm{AChE}$, estudos com fluoreto de sódio e oximas [2-aldoxima metiliodeto piridina (2-PAM) e 4-formilpiridinium dioxima brometo (TMB-4)] têm sido efetuados, obtendo-se até $60 \%$ de regeneração da atividade enzimática inicial. ${ }^{107,108}$ Metais pesados atuam inibindo enzimas pela ligação com grupamentos tiol protéicos. $\mathrm{O}$ uso de agentes quelantes, como o EDTA, pode regenerar a atividade catalítica da enzima. ${ }^{109,110}$ 
Tabela 1. Enzimas aplicadas na construção de biossensores baseados no princípio de inibição enzimática, reações catalisadas e inibidores potenciais

\begin{tabular}{|c|c|c|c|}
\hline enzima & reação catalisada & inibidor & Ref. \\
\hline Colina oxidase & colina $+\mathrm{O} 2 \rightarrow$ aldeído betaina $+\mathrm{H} 2 \mathrm{O} 2$ & $\begin{array}{c}\text { organofosforados, carbamatos, } \mathrm{Ag}+, \mathrm{Cu}+, \\
\mathrm{Hg} 2+\end{array}$ & $41,42,51,52,56,99$ \\
\hline Colinesterase & $\begin{array}{c}\text { acetil(butiril)colina }+\mathrm{H} 2 \mathrm{O} \rightarrow \text { colina }+ \text { ácido } \\
\text { acético }\end{array}$ & $\begin{array}{l}\text { organofosforados, carbamatos, metais. } \\
\text { nicotina, microcistinas }\end{array}$ & $\begin{array}{c}18,21,31-33,35 \\
36,39,42-45,47-55 \\
59-73,83\end{array}$ \\
\hline Fosfatase & $\begin{array}{c}\text { glucose-6-fosfato }+\mathrm{H} 2 \mathrm{O} \rightarrow \text { glucose }+ \text { fosfato } \\
\text { inorgânico }\end{array}$ & $\begin{array}{l}\text { organofosforados, carbamatos, microcis- } \\
\text { tinas }\end{array}$ & 95-98 \\
\hline Glucose oxidase & $\begin{array}{c}\text { beta-D-glucose }+\mathrm{O} 2 \rightarrow \mathrm{D} \text {-glucono-1,5-lactone } \\
+\mathrm{H} 2 \mathrm{O} 2\end{array}$ & $\begin{array}{l}\text { hidroxiquinolina, adenina nucleotídeo, } \\
\mathrm{Ag}+, \mathrm{Br}-, \mathrm{Cl}-, \mathrm{CN}-, \mathrm{CuSO} 4, \mathrm{Hg}+\text {, hidrazi- } \\
\text { na }\end{array}$ & $23,38,100,101$ \\
\hline Lactato desidrogenase & lactato $+\mathrm{NAD}+\rightarrow$ piruvato $+\mathrm{NADH}+$ & $\begin{array}{l}\text { fluoropiruvato, } \mathrm{ADP}, \mathrm{ATP}, \mathrm{Cd} 2+\text {, citrato, } \\
\mathrm{CO} 2 \text {, glutamato, } \mathrm{Hg} 2+, \mathrm{Mn} 2+\text {, piruvato }\end{array}$ & 100,101 \\
\hline Peroxidase & $\mathrm{ROOR}^{\prime}+$ doador $(2 \mathrm{e}-)+2 \mathrm{H}+\rightarrow \mathrm{ROH}+\mathrm{R}^{\prime} \mathrm{OH}$ & tiuréia, etilinotiuréia, sulfitos, mercúrio & $42,83,92-94$ \\
\hline Tirosinase & $\begin{array}{l}\text { monofenol }+1 / 2 \mathrm{O} 2 \rightarrow \text { O-diidroxifenol } \\
\text { O-diidroxifenol } \rightarrow \text { O-quinona }\end{array}$ & $\begin{array}{c}\text { carbamatos, organofosforados, atrazinas, } \\
\text { tiuréas, herbicidas, clorofenóis, agentes } \\
\text { quelantes }\end{array}$ & $\begin{array}{c}20,22,34,37 \\
38,40,74-90\end{array}$ \\
\hline Urease & uréia $+\mathrm{H} 2 \mathrm{O} \rightarrow \mathrm{CO} 2+2 \mathrm{NH} 3$ & metais, $\mathrm{Hg} 2+, \mathrm{Mg} 2+$, tiuréia & 105,106 \\
\hline
\end{tabular}

\section{CONCLUSÃO}

Nas últimas décadas, estão sendo efetuados esforços pela comunidade científica objetivando o desenvolvimento de metodologias mais seguras, buscando melhorar a seletividade e a sensibilidade dos biossensores enzimáticos baseados no monitoramento do processo de inibição por analitos potencialmente tóxicos. A maioria dos arranjos até então descritos na literatura apresentou excelentes resultados em amostras sintéticas, mas ainda não são suficientemente robustos para aplicações em amostras reais. Muitos ainda não apresentam seletividade adequada, como no caso dos biossensores baseados em AChE, que não são capazes de identificar um analito específico em amostras multicomponentes. $\mathrm{O}$ uso de enzimas modificadas geneticamente parece ser bastante promissor para minimizar esta problemática. A sensibilidade destes sistemas analíticos é suficiente para detectar praguicidas e metais pesados tóxicos nos níveis mínimos impostos por agências reguladoras, o que fortalece seu uso como metodologias screnning, efetuando a seleção de amostras potencialmente tóxicas, que podem então, posteriormente, ser analisadas por técnicas validadas. Dispositivos compactos e portáteis, com arranjos multissensores, capazes de detectar e diferenciar misturas multianalitos são atrativos significantes e podem ser descritos como o futuro da aplicação destes biossensores.

\section{REFERÊNCIAS}

1. Clarks, 1.; Lions, C.; Ann. N. Y. Acd Sci. 1962, 102, 29.

2. Fatibello Filho, O.; Capelato, M. D.; Quim. Nova 1992, 15, 28.

3. Karube, I.Em Handbook of Measurement Science; Sydenham, P. H.; Thom, R., eds.; Wiley: Chichester, 1992.

4. Guilbaut, C. C.; Montalvo, J. G.; J. Am. Chem. Soc. 1969, 91, 2164

5. Amine, A.; Mohammadi, H.; Bourais, I.; Palleschi, G.; Biosens. Bioelectron. 2006, 21,1405.

6. Castro, M. D. L.; Herrera, M. C.; Biosens. Bioelectron. 2003, 18, 279.

7. Patel, P. D.; TrAC, Trends Anal. Chem. 2002, 21, 96.

8. Mello, L. D.; Kubota, L. T.; Food Chem. 2002, 77, 237.

9. Bassi, A. S.; Tang, D.; Lee, E.; Zhu, J. X.; Bergougnou, M. A.; Food Technol. Biotechnol. 1996, 34, 9.

10. Kim, N.; Park, I.; Kim, D.; Biosens. Bioelectron. 2001, 22, 1593.

11. Lin, T.; Huang, K.; Liu, C.; Biosens. Bioelectron. 2006, 22, 513.

12. Narli, I.; Kiralp, S.; Toppare, L.; Anal. Chim. Acta 2006, 572, 25.
13. Rogers, K. R.; Anal. Chim. Acta 2006, 568,155.

14. Laschi, S.; OgoDczyk, D.; Palchetti, I.; Mascini, M.; Enzyme Microb. Technol. 2007, 40, 485.

15. Scheper, T. H. ; Hilmer, J. M.; Lammers, F.; Müller, C.; Reinecke. M.; J. Chromatogr., A 1996, 725, 3.

16. Thévenot, D. R.; Toth, K.; Durst. R. A.; Wilson. G. S.; Biosens. Bioelectron. 2001, 16,121.

17. Zhang, S.; Wright, G.; Yang, Y.; Biosens. Bioelectron. 2000, 15, 273.

18. Jin, S.; Xu, Z.; Chen, J.; Liang, X.; Wu, Y.; Qian, X.; Anal. Chim. Acta 2004, 523,117.

19. Krawczyk, T. K.; Moszczynska, M.; Trojanowicz, M.; Biosens. Bioelectron. 2000,15, 681 .

20. Chang, S. C.; Rawson, K.; Mcneil, C. J.; Biosens. Bioelectron. 2002, 17,1015 .

21. Marty, J. L.; Garcia, D.; Rouillon, R.; TrAC, Trends Anal. Chem. 1995, 14,3329

22. Besombes, J-L.; Cosnier, S.; Labbé, P.; Reverdy, G.; Anal. Chim. Acta 995, $311,255$.

23. Malitesta, C.; Guascito, M. R.; Biosens. Bioelectron. 2005, 20, 1643.

24. Mazzei, F.; Botrè, F.; Montilla, S.; Pilloton, R.; Podestá, E.; Botrè, C.; J. Electroanal. Chem. 2004, 574, 95.

25. Lehninger, A.; Nelson, D.; Cox, M. M.; Princípios de bioquímica, $3^{\mathrm{a}}$ ed. Sarvier: São Paulo, 2003.

26. Palmer, T.; Understanding enzymes, $3^{\text {rd }}$ ed., Ellis Horwood: New York, 1991.

27. Delvin, T. M.; Manual de bioquímica com correlações clínicas, $4^{\mathrm{a}}$ ed. Edgard Blucher: São Paulo,1998.

28. Dixon, M.; Webb, E. C.; Enzymes, $2^{\text {nd }}$ ed., Longmans: London, 1964.

29. Updike, S. J.; Hicks, G. P.; Nature 1967, 214, 986.

30. Albareda-Sirvent, M.; Merkoçi, A.; Alegret, S.; Sens. Actuators, B 2000, $69,153$.

31. Andreescu, S.; Noguer, T.; Magearu, V.; Marty, J-L.; Talanta 2002, 57, 169.

32. Nunes, S. N.; Jeanty, G.; Marty, J-L.; Anal. Chim. Acta 2004, 523, 107.

33. Gogol, E. V.; Evtugyn, G. A.; Marty, J-L.; Budnikov, H. C.; Winter, V. G.; Talanta 2000, 53, 379.

34. Wang, J.; Nascimento, V. B.; Kane, S. A.; Rogersb, K.; Smyth, M. R.; Angnes, L.; Talanta 1996, 43, 1903.

35. Cremisini, C.; Di Sario, S.; Mela, J.; Pilloton, R.; Palleschi, G.; Anal. Chim. Acta 1995, 311, 273. 
36. Palchetti, I.; Cagnini, A.; Carlo, M.; Coppi, C.; Mascini, M.; Turner, A P. F.; Anal. Chim. Acta 1997, 337, 31.

37. Wang, B.; Zhang, J.; Dong, S.; Biosens. Bioelectron. 2000,15, 397.

38. Retama, J. B.; López, M. S.; Pérez, J. P. H.; Cabanillas, G. F.; LópezCabarcos, E.; López-Ruiz, B.; Biosens. Bioelectron. 2005, 20, 2268.

39. Diaz, A. N.; Peinado, M. C. R.; Sens. Actuators, B 1997, 38, 426.

40. Vidal, J. C.; Esteban, S.; Gil, J.; Castillo, J. R.; Talanta 2006, 68, 791.

41. Yang, Y.; Yang, M.; Wang, H.; Jiang, J.; Shen, G.; Yu, R.; Sens. Actuators, B 2004, 102, 162.

42. Li, Y-G.; Zhou, Y-X.; Feng, J-L.; Jiang, Z-H.; Ma, L-R.; Anal. Chim. Acta 1999, 382, 277.

43. Reybier, K.; Zairi, S.; Jaffrezic-Renault, N.; Fahys, B.; Talanta 2002, 56,1015 .

44. Skládal, P.; Anal. Chim. Acta 1991, 252, 11.

45. Skladal, P.; Mascini, M.; Biosens. Bioelectron. 1992, 7, 335

46. Zhang, S.; Zhao H.; John, R.; Biosens. Bioelectron. 2001, 16, 1119.

47. Nunes, G. S.; Pesticidas R. Téc. Cient. 1996, 6, 13.

48. Ivanov, A. N.; Evtugyn, G. A.; Gyurcsányi, R. E.; Tóth, K.; Budnikov, H. C.; Anal. Chim. Acta 2000, 404, 55.

49. Marques, C. V. V. C. O.; Marques, P. R. B. O.; Nunes, G. S.; Pesticidas R. Téc. Cient. 2006, 16, 81 .

50. Andreescu, S.; Marty, J-L.; Biomol. Eng. 2006, 23, 1.

51. Kok, F. N.; Hasirci, V.; Biosens. Bioelectron. 2004,19, 661.

52. Guerrieri, A.; Palmisano, F.; Anal. Chem. 2001, 73, 2875.

53. Nunes, G. S.; Sklàdal, P.; Yamanaka, H.; Barcelo, D.; Anal. Chim. Acta 1998, 362, 59 .

54. Rippeth, J. J.; Gibson, T. D.; Hart, J. P.; Hartley, I. C.; Nelson, G.; Analyst 1997, 122, 1425.

55. Bucur, B.; Fournier, D.; Danet, A.; Marty, J-L.; Anal. Chim. Acta 2006 562,115 .

56. Ricci, F.; Palleschi, G.; Biosens. Bioelectron. 2005, 21, 389.

57. Salimi, A.; Sharifi, E.; Noorbakhsh, A.; Soltanian, S.; Biophys. Chem. 2007, 125,540

58. Tothill, I. E.; Comput. Electron. Agric. 2001, 30, 205.

59. Kumaran, S.; Morita, M.; Talanta 1995, 42, 649.

60. Lenigk, R.; Lam, E.; Lai, A.; Wang, H.; Han, Y.; Carlier, P.; Renneberg, R.; Biosens. Bioelectron. 2000, 15, 541.

61. Dzyadevych, S. V.; Soldatkin, A. P.; Arkhypova, V. N.; El'skaya, A. V.; Chovelon, J-M.; Georgiou, C. A.; Martelet, C.; Jaffrezic-Renault, N.; Sens. Actuators, B 2005,105, 81.

62. Hart, A. L.; Collier, W. A.; Janssen, D.; Biosens. Bioelectron. 1997, 12 , 645.

63. Nikolelis, D. P.; Simantiraki, M. G.; Siontorou, C. G.; Tothb, K.; Anal. Chim. Acta 2005, 537, 169

64. Gunther, A.; Bilitewsk, U.; Anal. Chim. Acta 1995, 300, 117

65. Ghous, T.; Townshend, A.; Anal. Chim. Acta 1998, 372, 379

66. Marty, J-L.; Mionetto, N.; Lacorte, S.; Barceló, B, D.; Anal. Chim. Acta 1995, 311, 265 .

67. Doong, R-A.; Tsai, H-C.; Anal. Chim. Acta 2001, 434, 239.

68. Wong, F. C. M.; Ahmad, M.; Heng, L. Y.; Peng, L. B.; Talanta 2006, 69, 888.

69. Andreou, V. G.; Clonis, Y. D.; Biosens. Bioelectron. 2002, 17, 61.

70. Choi, J-W.; Kim, Y-K.; Lee, I-H.; Min, J.; Lee, W-H.; Biosens. Bioelectron. 2001, 16, 937.

71. Andres, R. T.; Narayanaswamy, R.; Talanta 1997, 44, 1335.

72. Nunes, G. S.; Montesinos, T.; Marques, P. R. B. O.; Fourinier, D.; Marty, J-L.; Anal. Chim. Acta 2001, 434, 1.

73. Marques, P. R. B. O.; Nunes, G. S.; Santos, T. C. R.; Andreescu, S.; Marty, J-L.; Biosens. Bioelectron. 2004, 20, 825.

74. Nistor, C.; Emnéus. J.; Waste Management 1999, 19, 147.
75. Trojanowicz, M.; Electroanalysis 2002, 14, 1311.

76. Vieira,I. C.; Fatibello-Filho, O.; Anal. Chim. Acta 1999, 399, 287.

77. Liu, S.; Yu, J.; Ju, H.; J. Electroanal. Chem. 2003, 540, 61.

78. Mazzei, F.; Botrè, F.; Lorenti, G.; Simonetti, G.; Porcelli, F.; Scibona, G.; Botrè, C.; Anal. Chim. Acta 1995, 316, 79.

79. Yu, J.; Liu, S.; Ju, H.; Biosens. Bioelectron. 2003,19, 509.

80. Daigle, F.; Trudeau, F.; Robinson, G.; Smyth, M. R.; Leech, D.; Biosens Bioelectron. 1998, 13, 417.

81. Dantoni, P.; Serrano, S. H. P.; Oliveira Brett, A. M.; Gutz, I. G. R.; Anal. Chim. Acta 1998, 366, 137.

82. Shleev, S.; Tkac, J.; Christenson, A.; Ruzgas, T.; Yaropolov, A. I.; Whittaker, J. W.; Gorton, L.; Biosens. Bioelectron. 2005 20, 2517.

83. Tønning, E.; Sapelnikova, S.; Christensen, J.; Carlsson, C.; WintherNielsen, M.; Dock, E.; Solna, R.; Skladal, P.; Nørgaard, L.; Ruzgas, T.; Emnéus, J.; Biosens. Bioelectron. 2005, 21, 608.

84. Pita, M. T. P.; Reviejo, A. J.; Villena, F. J. M.; Pingarrón, J. M.; Anal. Chim. Acta 1997, 340, 89.

85. Reviejo, A. J.; Fernández, C.; Liu, F.; Pingarrón, J. M.; Wang, J.; Anal. Chim. Acta 1995, 315, 93.

86. Hipolito-Moreno, A.; León-González, M. E.; Pérez-Arribas, L. V.; PoloDíez, L-M.; Anal. Chim. Acta 1998, 362, 187.

87. Everett, W. R.; Rechnitz, G. A.; Anal. Chem. 1998, 70, 807.

88. Serra, B.; Jiménez, S.; Mena, M. L.; Reviejo, A. J.; Pingarrón, J. M.; Biosens. Bioelectron. 2002, 17, 217.

89. Deng, Q.; Dong, S.; Analyst 1996, 121,1979.

90. Campanella, L.; Bonanni, A.; Martini, E.; Todini, N.; Tomassetti, M.; Sens. Actuators, B 2005,111, 505.

91. Chen, X.; Hu, Y.; Wilson, G. S.; Biosens. Bioelectron. 2002, 17, 911.

92. Buck, S.; Stein, K.; Schwedt, G.; Anal. Chim. Acta 1999, 390, 141.

93. Adeyoju, O.; Iwuoha, E. I.; Smyth, M. R.; Anal. Chim. Acta 1995, 305, 57.

94. Han, S.; Zhu, M.; Yuan, Z.; Li, X.; Biosens. Bioelectron. 2001, 16, 9.

95. Mazzei, F.; Botrè, F.; Anal. Chim. Acta 1996, 336, 67.

96. Rivasseau, C.; Racaud, A. P.; Deguin, A.; Hennion, M. C.; Anal. Chim. Acta 1999, 394, 243.

97. SzydBowska, D.; Campas, M.; Marty, J-L.; Trojanowicz, M.; Sens. Actuators, B 2006, 113, 787

98. Campas, M.; Szydlowska, D.; Trojanowicz, M.; Marty, J-L.; Biosens. Bioelectron. 2005, 20, 1520 .

99. Lima, R. S.; Nunes, G. S.; Noguer, T.; Marty, J-L.; Quim. Nova 2006, 30,9 .

100. Cagnini, A.; Palchetti, I.; Lionti, I.; Mascini, M.; Turner, A. P. F. B.; Sens. Actuators, $B$ 1995, 24-25, 85

101. Abel, P. U.; Woedtke,T.; Schulz, B.; Bergann, T.; Schwock, A.; J. Mol. Catal. B: Enzym. 1999, 7, 93.

102. Przybyt, M.; Biosens. Bioelectron. 1998, 13, 471.

103. Fennouh, S.; Casimiri, V.; Geloso-Meyer, A.; Burstein, C.; Biosens. Bioelectron. 1998, 13, 903

104. Young, S. J.; Hart, J. P.; Dowman, A. A.; Cowell, D. C.; Biosens. Bioelectron. 2001, 16, 887

105. Tsai, H-C.; Doong, R-A.; Chiang, H-C.; Chen, K-T.; Anal. Chim. Acta 2003, $481,75$.

106. Hassan, S. S. M.; El-Bahnasawy, R. M.; Rizk, N. M.; Anal. Chim. Acta 1997, 351, 91

107. Gulla, K. C.; Gouda, M. D.; Thakur, M. S.; Karanth, N. G.; Biochim. Biophys. Acta 2002, 1597, 133

108. Kok, F. N.; Bozoglu, F.; Hasirci, V.; Biosens. Bioelectron. 2002, 17, 531

109. Mohammadi, H.; Amine, A.; Cosnier, S.; Mousty, C.; Anal. Chim. Acta 2005, 543,143 .

110. Malitesta, C.; Guascito, M. R.; Biosens. Bioelectron. 2005, 20, 1643. 